\title{
NOTA EDITORIAL: EL CRECIMIENTO ES UNA VOCACIÓN, UNA RESPONSABILIDAD Y UN TRABAJO DE EQUIPO
}

\section{Amigo, Adriana}

$Y$ hoy me encuentro nuevamente, escribiendo la editorial de nuestros Informes de Investigación del IIATA. Nuestro Número 5, Año 5.

No es una editorial común, pues éste no es un tiempo común. En los escenarios de pandemia mundial, decretada por la OMS, era muy difícil seguir caminado en el mismo recorrido. Ese recorrido, estaba vacío de personas, de personas físicas, pero sentía que el contenido era más profundo, más reflexivo aún, hacía tiempo que estábamos adentro y ya unos tantos meses en los que nos habíamos acostumbrado a salir de la zona de confort. La vida social se había como borrado de nuestra rutina, el mercado de la vanidad se había esfumado, los argumentos de compra venta ya no pasaban por cómo ser mejor a partir de una marca.

Lo amenazante y quizás también lo desafiante, es que todo esto nos había pasado en un soplo. No sé qué se podrá contar de ese afuera, más de lo que nos transmiten los medios de comunicación, si sé que puedo contar desde el adentro, desde mí adentro y desde el adentro de este querido Instituto: Instituto de Investigaciones y Asistencia Tecnológica en Administración.

A él llegué en el 2015. Ese día estaba reunida en una empresa, y recibo un llamado a mi móvil. El entonces, Director de la Escuela de Administración, Mag. Christian Gentili, me convocaba a la Dirección del Instituto, casi sin posibilidad a titubear.

No puedo negar la sumatoria de sensaciones, miedos, inseguridades, desafíos, la pregunta ¿Cómo empezar? ¿Cómo continuar? ¿Qué hacer?

Entonces recordé tres palabras de mi obra "Negocios con Valor", en las que citaba la reflexión de un famoso empresario en un Pre Coloquio empresarial. Él dijo, "los que llegamos hasta aquí, llegamos porque nos hemos permitido protagonizar tres verbos: Hacer, Deshacer, Rehacer". Cabe para nuestro hoy: hemos hecho, hemos deshecho, hemos rehecho. No es fácil. Pero nada más apasionante que lo difícil, lo que nos moviliza, lo que nos determina nuestro cambio de mirada, de actitud, de comprensión, de compromiso.

$Y$ hoy estoy escribiendo esta editorial para una nueva forma de comunicar nuestras producciones científicas, es un momento único, quedará en nuestra memoria. Esta es la primer editorial de nuestra primer revista online, pues nuestros Informes de Investigación, dejarán su versión papel, para indexarse y trascender de una manera distinta. 
En una de mis primeras editoriales para nuestra versión papel, reflexionaba sobre el recorrido del IIATA, y decía que era un recorrido que se había nutrido de etapas, exploración, metodología, grandes equipos, grandes personas, sueños y objetivos. Los principios claves de su misión, siguen intactos, vivos y en acción:

- Promover la difusión de los resultados de las investigaciones y la producción de publicaciones en jornadas, congresos, eventos nacionales e internacionales

- Estimular el desarrollo científico (con pertinencia social)

- Fomentar la formación de recursos humanos, mediante la incorporación de los alumnos de grado, de posgrado y ayudantes de investigación a los equipos de investigación.

- Lograr la coordinación interdisciplinaria

Jean Paul Sartre, escribe en 1943, su obra maestra "El ser y la nada", su obra más importante, en la que distingue "el-ser-en-si" y "el-ser-para-sí": lo que es y no puede dejar de ser para ser otra cosa y el ser que puede proyectarse y salir de sí; pero que también es y logra ser todo aquello que eligió. Me siento inspirada en esas dos apreciaciones, para estar segura, que este escalón, lo hemos elegido juntos, todos los Docentes Investigadores del Instituto, que me acompañaron desde ese maravilloso 2015, en donde desde mi ser y mi nada, tomé el compromiso de caminar hacia el futuro, aglutinando al IIATA sobre círculos virtuosos. Como expresa este gran filósofo del siglo XX, "Somos lo que elegimos ser, somos libres para elegir y ser lo que deseamos ser" Entonces la libertad del ser, nos permite tomar la decisión del cambio. Estamos cambiando el medio, pero no la esencia. $Y$ el espíritu libre y ético del investigador, hoy está presente más que nunca, en una sociedad en donde la conciencia de la crisis, los escenarios de incertidumbre y el compromiso social, nos imponen el límite ético a esa libertad creativa.

Mis agradecimientos, siempre a la Decana de nuestra Facultad y a todo su gran equipo de gestión, Mag. Adriana Racca, pues su crédito y apoyo, nos permite caminar hacia el futuro; a la Directora de la Escuela de Administración, CP Adriana Daffunchio, al alentar, apoyar y motivar nuestro recorrido, al Secretario de Ciencia y Tecnología de nuestra Facultad, Dr. Hernán Lapelle, quien me alentó sinceramente a vencer los miedos y tomar esta nueva dirección de crecimiento, a la Dra. Carmen Verón, quien me enseñó los primeros pasos para hacer la revista versión papel, al Mag. Carlos Authier, del CONICET, que nos permite con su apoyo al IIATA, aprender sobre cómo normalizar una publicación científica, al Mag. Guillermo Peinado, quien con su grandeza y generosidad, nos ha permitido entrar y comenzar a aprender este nuevo derrotero volcándonos todo el expertise de Saberes, al Secretario Financiero de 
nuestra Facultad, CP Sergio González, por permitir el hacer, a Mag. Paola Bongiovanni, quien desde la UNR, nos está enseñando a recorrer y construir nuestra visibilidad, al equipo de Informática de nuestra Facultad, en especial a Cristian Liendo y a mis dos colaboradoras directas: Lic. Florencia Guisen y Tec. María de los Ángeles González, quienes en la labor de gestión y edición, suman un gran esfuerzo a una realidad, que ya dejó de ser un sueño.

El reconocimiento y gratitud a todos los Docentes Investigadores que hoy enriquecen nuestra primer edición de Informes de Investigación IIATA, on line, Año 5, Número 5, habiendo generado una edición interdisciplinaria, con aportes provenientes no solo de nuestra Facultad, sino de otras Facultades Nacionales, Organismos Públicos y Entidades Intermedias.

La motivación, nos moviliza a las ganas de crecer; la unión nos compromete a la mirada compartida; el espíritu exploratorio, nos marca el camino de la búsqueda. Que esa búsqueda, esté apalancada en la ética y en el protagonista principal de la historia: el conocimiento. Nuevamente, ¡Gracias! 